\title{
Aldosteronoma causing Conn's syndrome: a case report and literature review
}

\author{
Hsin-Hui Shao ${ }^{1}$, Hock-Liew Eng ${ }^{2}$, Wen-Sheng Huang ${ }^{3}$, Joseph Nybo Lin ${ }^{4}$ \\ ${ }^{1}$ Department of Family Medicine, Mackay Memorial Hospital, Hsinchu Branch, Taiwan, China \\ ${ }^{2}$ Department of Pathology, Chang Gung Memorial Hospital, Taiwan, China \\ ${ }^{3}$ Department of Nuclear Medicine, Tri-Service General Hospital, Taiwan, China \\ ${ }^{4}$ Johns Hopkins University, School of Public Health, Baltimore, Maryland, USA; josephsimion@hotmail.com
}

Received 17 November 2009; revised 28 November 2009; accepted 29 November 2009.

\begin{abstract}
We report a case of primary aldosteronism caused by bilateral solitary aldosteronomas occurring 6 months apart, the diagnosis being confirmed by clinical features. Multiple aldosterone-producing adenomas can be unilateral or bilateral. If bilateral, most of them are found simultaneously. Bilateral solitary aldosteronomas occurring at separate times are rarely reported and the pathogenesis is still elusive. We believe, from this case, the postoperative follow-up in patients with primary aldosteronism is mandatory.
\end{abstract}

Keywords: Adrenal Tumor; Aldosteronism; Bilateral Aldosterone-Producing Adenomas; Aldosteronoma; Adrenectomy

\section{INTRODUCTION}

The most frequent causes of mineralocorticoid hypertension are primary hyperaldosteronism (Conn's syndrome) due to a solitary aldosterone-producing adenoma (APA) and bilateral hyperplasia aldosteronism (BHA). Surgery is the treatment of choice for APA [1,2], but not for BHA [3]. Correct management depends on the physicians' ability to tell the difference between these two diseases, and several methods have been devised to aid this distinction [4]. We report a rare case of bilateral solitary adrenocortical adenomas causing primary hyperaldosteronism at separate periods 6 months apart, the diagnosis confirmed by clinical features, operation, and pathology.

\section{CASE REPORT}

The subject, a 40-year-old woman in 2000, visited our endocrine outpatient clinic with the main complaint of recurrent hypertension for four years after left total adrenectomy about five years ago.
According to her past medical history, hypertension (systolic BP $190 \mathrm{mmHg}$, diastolic BP $110 \mathrm{mmHg}$ ) and hypokalemia (2.5 meq/l) were first recorded at a regional tertiary hospital in 1995. A morning ambulatory test was done under the suspicion of hyperaldosteronism. Plasma cortisol concentration, $17.2 \mathrm{ug} / \mathrm{ml}$ at 08:00 h (normal: 9-23 ug/dl) and $1.7 \mathrm{ug} / \mathrm{ml}$ at midnight, showed a normal circadian drop throughout the test. Upright plasma aldosterone level was $703 \mathrm{pg} / \mathrm{ml}$ (normal: $40-310 \mathrm{pg} / \mathrm{ml}$ ) at 08:00 h, and it decreased slightly after four hours of walking $(652 \mathrm{pg} / \mathrm{ml})$. And the upright plasma aldosterone/plasma renin activity ratio was greater than 30 . Plasma renin level was still suppressed throughout the test (data not shown). Abdomen computerized tomography (CT) revealed a $1 \times 1.5 \mathrm{~cm}$ hypodense mass over the left adrenal gland (Figure 1), and controlateral adrenal appearance was normal at CT scan. Adrenal vein sampling analyses showed that the aldosterone level from the left adrenal vein $(743 \mathrm{pg} / \mathrm{ml})$ greatly exceeded that from the right adrenal vein $(131 \mathrm{pg} / \mathrm{ml})$. The diagnosis of primary aldosteronism due to an aldosterone-producing adenoma of the left adrenal gland was therefore confirmed.

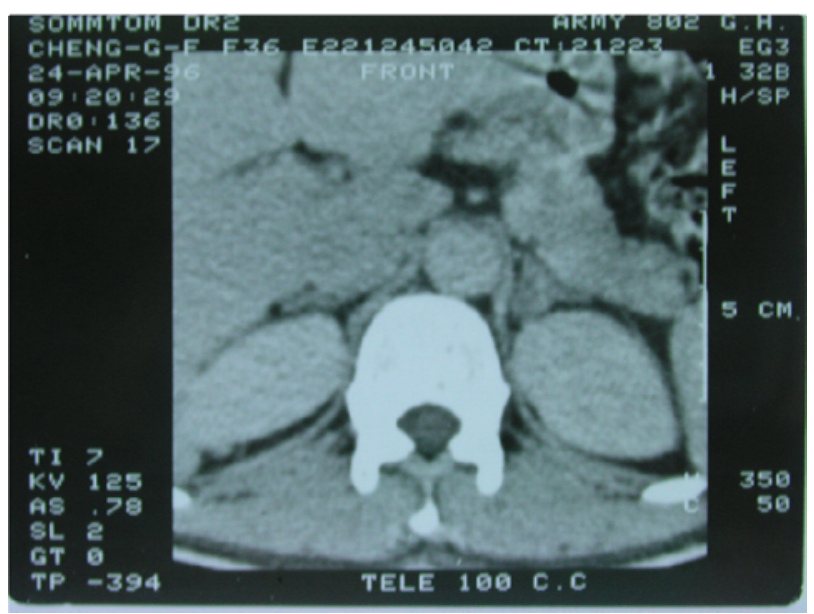

Figure 1. Abdomen CT with enhancement revealed a tumor in left adrenal gland (black arrow). 




(a)

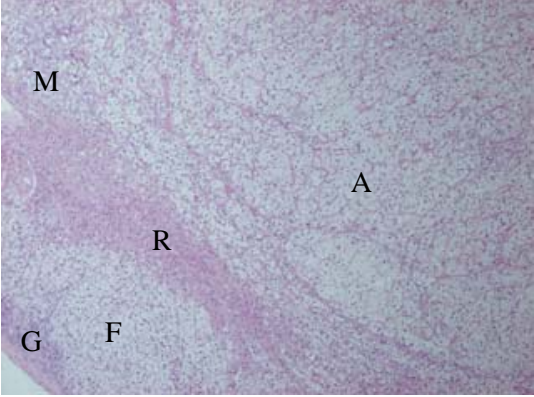

(b)

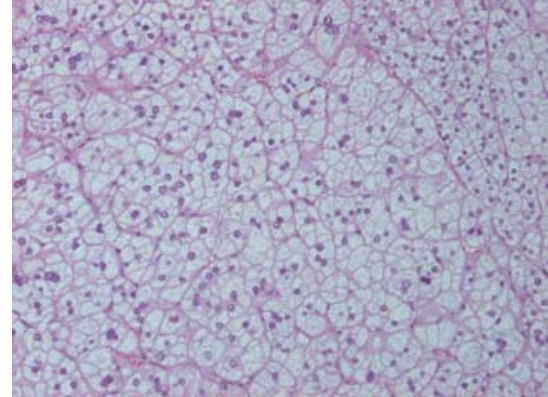

(c)

Abbreviations: (C) capsule, (G) zone glomerulosa, (F) zone fasciculata, (R) zone reticularis, (M) medulla, (A) adenoma.

Figure 2. (a) Normal part of left adrenal gland (H\&E, x40); (b) A part of adenoma and adjacent normal tissue in left adrenal gland (H\&E, x40); (c) A part of adenoma of left adrenal gland (H\&E, x100). Cells were large, clustered, and clear-lipid filled.

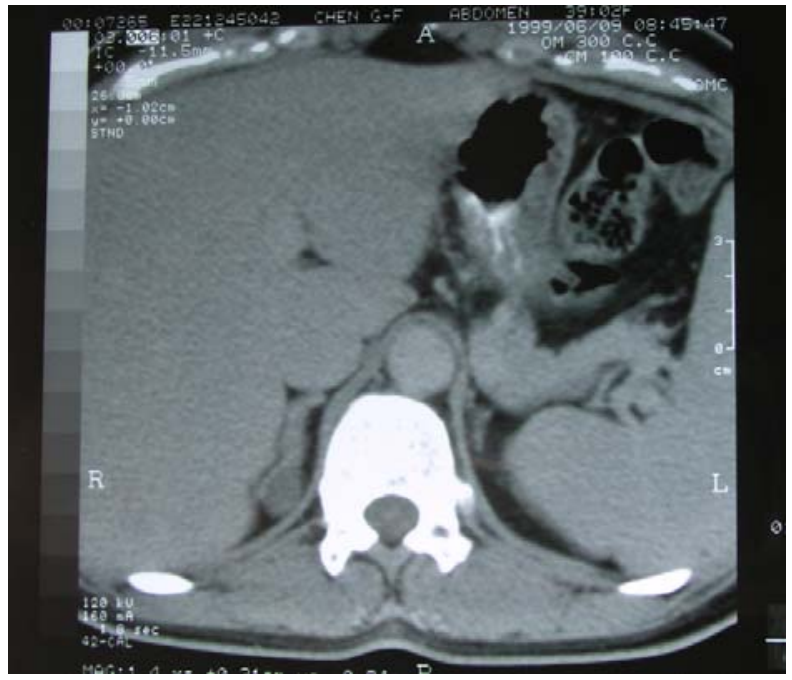

(a)

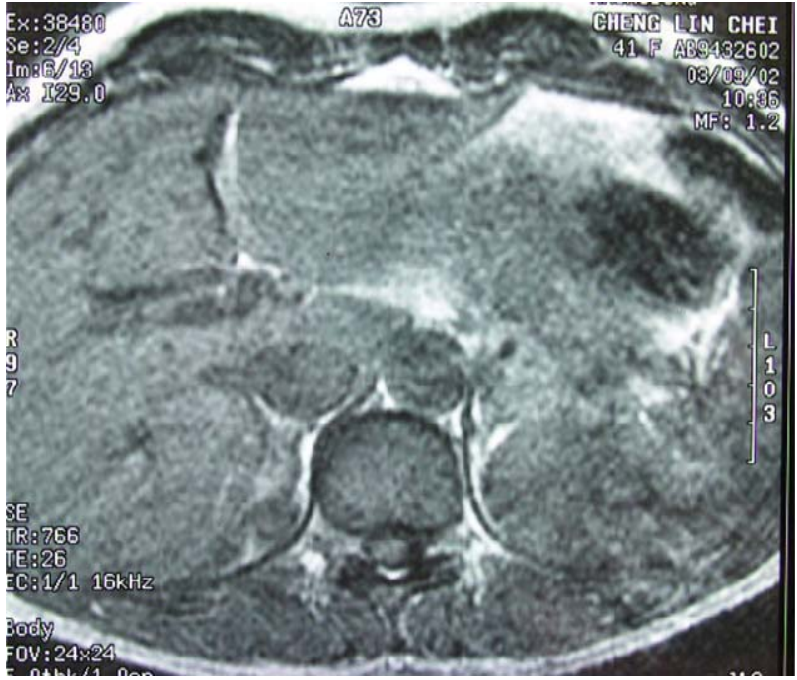

(b)

Figure 3. (a) Abdomen CT with enhancement in June 1999 and (b) follow-up abdomen MRI in March 2002 both revealed a tumor in right adrenal gland (black arrows) and left adrenal was absent.

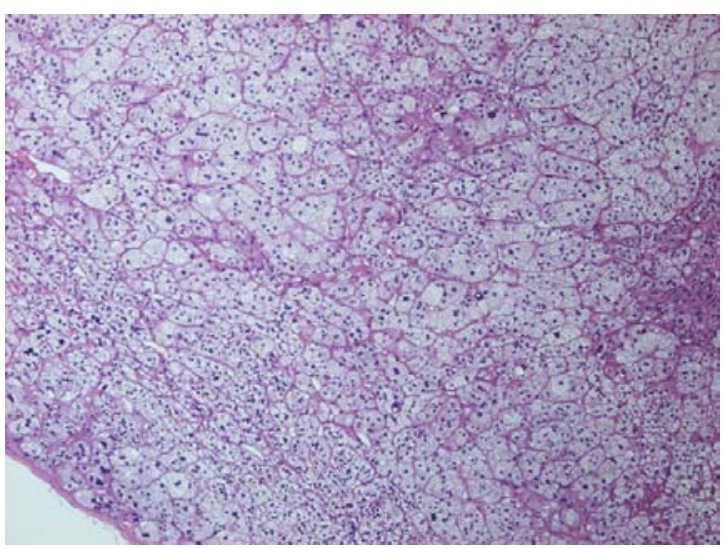

(a)

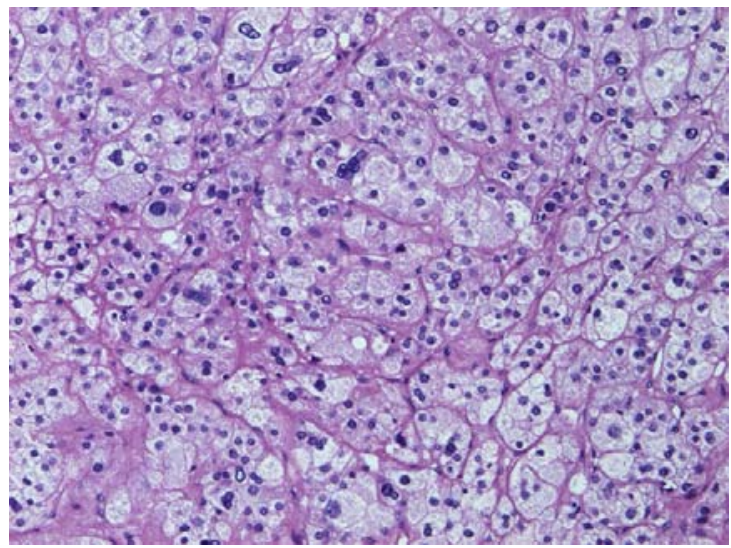

(b)

Figure 4. A part of adenoma. Right adrenal gland. (a) H\&E, x40; (b) H\&E, x100.

The patient underwent left side total adrenectomy in May 1996. The pathology report showed a well-encapsulated nodule measuring $1.4 \times 1.7 \times 1.2 \mathrm{~cm}$, composed mainly of clear cells in cords and clusters, and the diagnosis of adrenal cortical adenoma was favored. There was no hyperplastic change or other adenoma noted in the adja- 
cent adrenal cortical tissue (Figure 2). One week after operation, the serum potassium $(\mathrm{K})$ level returned to normal range ( $4.3 \mathrm{meq} / \mathrm{l})$, and the sequential measurement of her plasma aldosterone $43 \mathrm{pg} / \mathrm{ml}$ and plasma renin $10.1 \mathrm{uU} / \mathrm{ml}$ (normal: 7 to $76 \mathrm{uU} / \mathrm{ml}$ ) revealed within normal limits.

Thereafter, her blood pressure (systolic BP 105-110 $\mathrm{mmHg}$, diastolic BP 65-80 mmHg) and serum potassium level (3.6-4.3 meq/l) remained normal after operation without any medication. However, recurrence of hypertension and hypokalemia developed after half a year, and she was treated with amlodipine $5 \mathrm{mg}$ once daily regularly and potassium chloride tablet when needed. Her blood pressure was not well controlled by the medication, and follow-up abdomen CT in June 1999 revealed a small nodule about $1 \times 1 \mathrm{~cm}$ over the right adrenal gland (Figure 3(a)). She was then referred to our endocrine clinic for further management in July 2000.

Physical examination revealed hypertension (168/109 $\mathrm{mmHg}$ ) and tachycardia (108/min); the other findings were unremarkable. There was no contributory family history of hypertensive disease. Laboratory data under amlodipine and potassium chloride treatment showed serum sodium (Na) level of $142 \mathrm{meq} / \mathrm{l}$ (normal: 135-145 meq/l), K $2.1 \mathrm{meq} / \mathrm{l}$ (normal: 3.6-4.8 meq/l), creatinine $0.6 \mathrm{mg} / \mathrm{dl}$ (normal: $0.4-1.4 \mathrm{mg} / \mathrm{dl}$ ), $08: 00 \mathrm{~h}$ cortisol $10.1 \mathrm{ug} / \mathrm{ml}$ (normal: 9-23 ug/dl), 08:00 h ACTH 96.7 pg/ml (normal: 9-52 pg/ml), upright aldosterone $689 \mathrm{pg} / \mathrm{ml}$ (normal: 29-162 pg/ml), and the upright plasma aldosterone/plasma renin activity ratio was greater than 30. 24 hr urinary vanillylmandelic acid excretion was normal. Recurrent primary hyperaldosteronism was highly suspected. After withdrawal of amlodipine and potassium chloride tablet, ${ }^{131}$ I-6-beta-iodomethyl-norcholesterol (NP-59) adrenal scintiphotographic study under dexamethasone suppression (1 mg four times a day) revealed early visualization of the right adrenal gland, suggesting hyperfunction of the remaining right adrenal gland. Repeated laboratory data during the examination of adrenal scintiphotography showed Na $141 \mathrm{meq} / \mathrm{l}$, K $2.7 \mathrm{meq} / \mathrm{l}$, and aldosterone $567 \mathrm{pg} / \mathrm{ml}$. Plasma renin level was also low throughout the test (data not shown). Other endocrine hormone analyses remained within normal limits including prolactin $22.6 \mathrm{ng} / \mathrm{ml}$, growth hormone $0.05 \mathrm{ng} / \mathrm{ml}$, intact parathyroid hormone (iPTH) $7.2 \mathrm{pg} / \mathrm{ml}$, fasting insulin $5.1 \mathrm{uIU} / \mathrm{ml}$, gastrin $49.1 \mathrm{pg} / \mathrm{ml}$, calcitonine $2.3 \mathrm{pg} / \mathrm{ml}$, and carcinoembryonic antigen (CEA) $1.8 \mathrm{pg} / \mathrm{ml}$.

The patient was then placed on captopril $25 \mathrm{mg}$ twice daily and spironolactone 50mg twice daily in December 2000. The following treatment course was smooth, and her blood pressure and serum $\mathrm{K}$ level returned to normal range (systolic BP 110-120 mmHg, diastolic BP 70-80 $\mathrm{mmHg}$, and $\mathrm{K}$ 3.5-4.1 meq/l) with regular medication until March 2002, when higher blood pressure (systolic BP 134-147 mmHg, diastolic BP 90-110 mmHg) recurred, and she began to feel fatigue again. Abdomen magnetic resonance imaging (MRI) revealed a 1.5x1.2 cm mass over the right adrenal gland (Figure 3(b)), so she underwent right retroperitoneoscopic adrenal tumor resection (partial adrenectomy) in April 2002. The pathology report showed a $2.4 \times 1.7 \times 0.8 \mathrm{~cm}$ mass composed of nests of large lipid-rich cells and some lipidpoor cells, and the diagnosis of adrenal cortical adenoma was favored (Figure 4).

Three days after operation, her aldosterone level was below 25 pg/ml. Since the patient's discharge, her blood pressure and potassium level have remained normal (systolic BP 90-120 mmHg, diastolic BP 60-80 mmHg, $\mathrm{K}$ 4.0-4.3 meq/l) for more than one year without any medication. Her plasma cortisol level has been within normal limits after operation. Other endocrine hormone analyses, including prolactin, growth hormone, iPTH, fasting insulin, gastrin, calcitonine, and CEA, have remained within normal limits throughout the course.

\section{DISCUSSIONS}

The primary function of aldosterone is regulation of extracellular volume and control of potassium homeostasis [5]. Primary hyperaldosteronism, the cause of approximately $0.05 \%$ to $2.2 \%$ of all secondary hypertension, is characterized by suppressed plasma renin activity and hypokalemia [1]. Recognized etiologies include unilateral APA, BHA, adrenocortical carcinoma, and glucocorticoid-remediable aldosteronism (GRA). Solitary APA is the most common cause of primary aldosteronism and accounts for approximately 65\% of cases; BHA accounts for $30 \%$ to $35 \%$ and GRA fewer than 3\% [6]. Bilateral solitary aldosteronomas occurring separately and causing primary hyperaldosteronism are rarely reported. From literature, simultaneous presence of unilateral multiple APA $[7,8]$, a hyperfunctioning aldosteronoma with a minimally functioning adenoma on the other side [9], or simultaneous bilateral functioning aldosteronomas [10] have been described. Furthermore, recurrence of APA in the same adrenal gland [11] 9 years apart has also been mentioned. The incidence of multiple APA varied from $3.9 \%$ to $10 \%$ according to different reports $[7,8,12]$, suggesting the real incidence may be higher than we expected.

The clinical pictures of our case were not very different from a typical unilateral APA before her first operation. First, morning ambulation has been used to evaluate the suppression of aldosterone by monitoring plasma cortisol and aldosterone to upright ambulation [13]. In patients with APA, aldosterone levels generally decline in parallel with circadian secretion of cortisol [14]. In contrast, in patients with BHA, there is usually an increase in renin and aldosterone levels in response to upright posture. In our case, plasma cortisol concentration showed a normal circadian drop throughout the test. The 
plasma aldosterone level was much higher at 08:00 h, and had decreased slightly after four hours of walking. Plasma renin level was suppressed throughout the test. Image study for the differential diagnosis of a unilateral adenoma or bilateral hyperplasia includes a CT scan or MRI. The sensitivity of CT to distinguish solitary APA and BHA has been reported at 85\% [15] or higher [16]. In our case, the CT image in 1995 revealed a well-defined mass over the right adrenal gland and normal appearance of the left adrenal gland. However, if the CT scan or MRI is normal, or if bilateral nodular hyperplasia cannot be ruled out, adrenal vein aldosterone sampling may be considered as a next step. Adrenal vein sampling, having the value of physiologic localization, has been one of the first tests used to distinguish between APA and BHA [17]. The aldosterone level from the left adrenal vein was five times greater than that from the right adrenal vein in our case. This result was compatible with the key diagnostic feature of unilateral adenoma, which requires a unilateral two to threefold elevation of aldosterone [18]. However, there was no further scintiphotography performed in 1995 to evaluate the functional status of the other adrenal gland.

In 1999, CT image in our case showed another well-defined mass over the right adrenal gland. The patient's left adrenal had already been removed. What we needed to do was to confirm the hyperfunctional state of her remaining right adrenal gland, and it was proved by the NP-59 adrenal scintiscan. NP-59 scintiscan has been reported as a unique imaging technique because it can depict the functional status of the adrenals in syndromes with hypersecretion of glucocorticoid, mineralcorticoid or androgen hormones [19]. The diagnostic sensitivity of the NP-59 adrenal scintiscan in the localization of aldosteronomas with adequate dexamethasone suppression may be more than $80 \%$ to $97 \%$ [20-22].

Glucocorticoid-remediable aldosteronism (GRA) is another rare form of hyperaldosteronism [23]. GRA is usually associated with bilateral adrenal hyperplasia, the plasma potassium concentration is normal in more than half of all cases of GRA. The circadian rhythm of aldosterone release in GRA is primary under the influence of ACTH release. Therefore, in our practice, we used dexamethasone suppression test [24] to rule out the possibility of GRA during the adrenalscintiphotographic study.

Surgical treatment is very effective in cases due to APA [25], whereas surgery in BHA is seldom curative [12]. Early normalization of blood pressure [7] and potassium level [26] has been reported in the postoperative course of APA. Normalization may take up to one month but is usually achieved within one week after surgery. In our case, the patient's laboratory data improved within one week of operation, and she was symptom-free without any medication after surgery for at least half a year, suggesting that BHA is unlikely. More importantly, three experienced pathologists confirmed that the normal adrenal tissue surrounding the adenoma showed no hyperplasic changes, which is present in typical BHA.

The underlying pathogenesis of bilateral solitary aldosteronoma occurring six months apart in our case is still unknown, although we have formed several hypotheses. First of all, it was possible that there was coexistence of bilateral adenomas initially. The left adrenal adenoma was well differentiated and secreted excess aldosterone, while the right adrenal adenoma remained in the stage of cell proliferation without hypersecretion. This phenomenon has been observed in a patient with ACTH-independent Cushing's syndrome [27]. It is therefore possible in our case that the right adrenal adenoma became autonomous and progressively enlarged after removal of the left adrenal adenoma. Since we did not perform functional scintiscan of the bilateral adrenal glands before the first operation, there was no sufficient data to support this hypothesis. Secondly, benign enlargement of the adrenal cortex has been found in about one third of the cases of multiple endocrine neoplasia type 1 (MEN 1), and rarely an aldosterone-producing adenoma has been described [28,29]. However, the other endocrine hormone analyses in our case, including plasma parathyroid hormone, gastrin, insulin, or prolactin, remained within normal limits, so early presentation of MEN 1 was not likely at present. Thirdly, bilateral aldosteronoma secondary to long-term hyperreninemia has been reported [30]. However, plasma renin level in our case was low throughout the course, and there was no evidence of renal artery stenosis or renal ischaemia in our case. Finally, an increased prevalence of adrenal lesions in patients with familial adenomatous polyposis (FAP) has been reported [31]. Most of these lesions are nonfunctioning adenomas, and some patients have hypercortisolism. A sporadic case of FAP with mineralocorticoid excess due to APA also has been reported [32]. In our case, there was no contributory family history of hypertensive disease, and her occult blood test of routine stool exam was negative.

In summary, although unilateral solitary APA is the most common cause of primary aldosteronism, multiple or bilateral hyperfunctioning adenomas may be more frequent than previously thought. Postoperative follow- up in patients with primary aldosteronism is worth our attention. Long-term monitoring of blood pressure and serum potassium level in these patients is mandatory. 


\section{REFERENCES}

[1] Conn, J.W. and Louis, L.H. (1956) Primary aldosteronism: A new clinical entity. Ann Intern Med, 44, 1-15.

[2] Lo, Y.C., Tam, P.C., Kung, A.W., Lam, K.S., and Wong, J. (1996) Primary aldosteronism results of surgical treatment. Ann Surg, 224, 125-130.

[3] Bravo, E.L., Tarazi, R.C., Dustan, H.P., et al. (1983) The changing clinical spectrum of primary aldosteronism. Am $J$ Med, 74, 641-651.

[4] Phillips, J.L., Walther, M.M., Pezzullo, J.C., et al. (2003) Predictive value of preoperative tests in discriminating bilateral adrenal hyperplasia from an aldosterone-producing adrenal adenoma. J Clin Endocrinol Metab, 85, 45264533.

[5] Mortensen, R.M. and Williams, G.H. (2001) Aldosterone action. In: DeGroot, L.J. and Jameson, J.L. eds. Endocrinology, Philadelphia: W.B. Saunders, Forth Edition, 1783-1790.

[6] Melby, J.C. (1991) Diagnosis of hyperaldosteronism. Endocrinol Metab Clin North Am, 20, 247-255.

[7] Ito, Y., Fujimoto, Y., Obara, T., and Kodama, T. (1990) Clinical significance of associated nodular lesions of the adrenal in patients with aldosteronoma. World J Surg, 14, 330-334.

[8] Liu, D., Chen, Q., and Zheng, C. (1995) Evaluation of surgical treatment for patients with multiple aldosteronoma: Analyses of 11 cases. China Surgery, 33, 681-683.

[9] Engel, J.D., Angelos, P., Rege, R.V., and Joehl, R.J. (1998) Bilateral adrenal cortical adenomas in primary hyperaldosteronism. Urology, 52, 711-714.

[10] Yamamoto, H., Sato, T., and Kato, Y. (1993) A rare case of primary aldosteronism due to bilateral functioning adrenocortical adenomas. Nippon Naibunpi Gakkai Zasshi, 69, 125-134.

[11] Calvo-Romero, J.M. and Ramos-Salado, J.L. (2000) Recurrence of adrenal aldosterone-producing adenoma. Postgrad Med J, 76, 160-161.

[12] Auda, S.P., Brennan, M.F., and Gill, J.R. (1980) Evolution of the surgical management of primary aldosteronism. Ann Surg, 191, 1-7.

[13] Fontes, R.G., Kater, C.E., Biglieri, E.G., and Irony, I. (1991) Reassessment of the predictive value of the postural stimulation test in primary aldosteronism. Am J Hypertens, 4, 786-791.

[14] Ganguly, A., Dowdy, A.J., Luetscher, J.A., and Melada, G.A. (1973) Anomalous postural response of plasma aldosterone concentration in patients with aldosteroneproducing adrenal adenoma. J Clin Endocrinol Metab, 36, 401-404.

[15] Lumachi, F., Marzola, M.C., Zucchetta, P., et al. (2003) Non-Invasive adrenal imaging in primary aldosteronism: Sensitivity and positive predictive value of radiocholesterol scintigraphy, CT scan and MRI. Nucl Med Commun, 24, 683-688.

[16] Lingam, R.K., Sohaib, S.A., Vlahos, I., et al. (2003) CT of primary hyperaldosteronism (Conn's syndrome): The value of measuring the adrenal gland. Am J Roentgenol, 181, 843-849.
[17] Young, W.F. and Klee, G.G. (1988) Primary aldosteronism: Diagnostic evaluation. Endocrinol Metab Clin North Am, 17, 367-395.

[18] Williams, G.H. and Dluhy, R.G. (2001) Disorders of the adrenal cortex. In: Braunwald, E., Fauci, A.S., Kasper, D.L., Hauser Longo, D.L., Jameson, J.L. eds. Harrison's Principles of Internal Medicine, New York: McGrawHill., Fifteenth Edition, 2084-2105.

[19] Lieberman, L.M., Beierwaltes, W.H., Conn, J.W., Ansari, A.N., and Nishiyama, H. (1971) Diagnosis of adrenal disease by visualization of human adrenal glands with 131 I-19-iodocholesterol. N Engl J Med, 285, 1387-1393.

[20] Freitas, J.E., Grekin, R.J., Thrall, J.H., Gross, M.D., Swanson, D.P., and Beierwaltes, W.H. (1979) Adrenal imaging with iodomethyl-norcholesterol (I-131) in primary aldosteronism. J Nucl Med, 20, 7-10.

[21] Taillefer, R., Soucy, J.P., Eybalin, M.C., and Levasseur, A. (1983) 131I-iodocholesterol (NP-59) scintigraphy in adrenocortical diseases. J Can Assoc Radiol, 34, 120-124.

[22] Ou, Y.C., Yang, C.R., Chang, C.L., Hwang, T.I., Chang, C.H., Wu, H.C., Ho, Y.J., and Kao, C.H. (1994) Comparison of five modalities in localization of primary aldosteronism. Chinese Medical Journal (Taipei), 53, 7-12.

[23] Dluhy, R.G. and Lifton, R.P. (1994) Glucocorticoidremediable aldosteronism. Endocrinol Metab Clin North Am, 23, 285-297.

[24] Litchfield, W.R., New, M.I., Coolidge, C., Lifton, R.P., and Dluhy, R.G. (1997) Evaluation of the dexamethasone suppression test for the diagnosis of glucocorticoid-remediable aldosteronism. J Clin Endocrinol Metab, 82, 3570-3573.

[25] Blumenfeld, J.D., Sealey, J.E., Schlussel, Y., et al. (1994) Diagnosis and treatment of primary hyperaldosteronism. Ann Intern Med, 121, 877-885.

[26] Obara, T., Ito, Y., Okamoto, T., et al. (1992) Risk factors associated with postoperative persistent hypertension in patients with primary aldosteronism. Surgery, 112, 987993.

[27] Iwase, K., Nagasaka, A., Tsujimura, T., et al. (1994) Cushing's syndrome with cortisol hypersecretion from one of bilateral adrenocortical adenomas: Report of a case. Surg Today, 24, 538-543.

[28] Skogseid, B., Larsson, C., Lindgren, P.G., et al. (1992) Clinical and genetic features of adrenocortical lesions in multiple endocrine neoplasia type 1. J Clin Endocrinol Metab, 75, 76-81.

[29] Zwermann, O., Beuschlein, F., Mora, P., Weber, G., Allolio, B., and Reincke, M. (2000) Multiple endocrine neoplasia type 1 gene expression is normal in sporadic adrenocortical tumors. Eur J Endocrinol, 142, 689-95.

[30] Vircburger, M.I., Prelevic, G.M., Todorovic, P., Bojic, P., Peric, L.A., and Paunkovic, N. (1984) Renovascular hypertension associated with bilateral aldosteronoma. Postgrad Med J, 60, 533-536.

[31] Marchesa, P., Fazio, V.W., Church, J.M., and McGannon, E. (1997) Adrenal masses in patients with familial adenomatous polyposis. Dis Colon Rectum, 4, 1023-1028.

[32] Alexander, G.L., Thompson, G.B., and Schwartz, D. (2000) Primary aldosteronism in a patient with familial adenomatous polyposis. Mayo Clin Proc, 75, 636-637. 